\title{
Biodegradable polysarcosine with inserted alanine residues: Synthesis and enzymolysis
}

\author{
Peng Zhou ${ }^{1}$, Tianlun Shen ${ }^{1,2}$, Wanli Chen ${ }^{3}$, Jihong Sun ${ }^{2}$, Jun Ling ${ }^{1, *}$ \\ 1 MOE Key Laboratory of Macromolecular Synthesis and Functionalization, \\ Department of Polymer Science and Engineering, Zhejiang University, Hangzhou \\ 310027, China. \\ ${ }^{2}$ Department of Radiology, Sir Run Run Shaw Hospital, Zhejiang University School of \\ Medicine, Hangzhou 310016, China. \\ ${ }^{3}$ Center of Analysis \& Measurement, Zhejiang University of Technology, Hangzhou \\ 310014, China. \\ *Corresponding author: lingjun@zju.edu.cn
}

\begin{abstract}
Polysarcosine (PSar), a water-soluble polypeptoid, is gifted with biodegradability via random ring-opening copolymerization of sarcosine- and alanine$N$-thiocarboxyanhydrides catalyzed by acetic acid in controlled manners. Kinetic investigation reveals the copolymerization behavior of the two monomers. The random copolymers, named PAS, with high molecular weights between 22.0 and $43.6 \mathrm{~kg} / \mathrm{mol}$ and tunable Ala molar fractions varying from $6 \%$ to $43 \%$ are able to be degraded by porcine pancreatic elastase within 50 days in mild conditions $\left(\mathrm{pH}=8.0\right.$ at $\left.37^{\circ} \mathrm{C}\right)$. Both the biodegradation rate and water solubility of PAS depend on the content of Ala residues. PAS with Ala fractions below $43 \%$ are soluble in water while the one with $43 \%$ Ala self-assembles in water into nanoparticles. Moreover, PAS are non-cytotoxic at the concentration of $5 \mathrm{mg} / \mathrm{mL}$. The biodegradability and biocompatibility endow the Alacontaining PSar with potential to replace PEG as protective shield in drug-delivery.
\end{abstract}

Key words: Poly(alanine- $r$-sarcosine), biodegradability, biocompatibility, alanineNTA, sarcosine-NTA. 

Precision pharmacotherapy in vivo is becoming a popular and promising research field where drug-delivery method plays a vital role in sending drugs to nidus. ${ }^{1-2}$ Since some pharmaceuticals or medicinal proteins are hydrophobic, it is necessary to modify the hydrophobes with hydrophiles in order to increase their water solubility and hydrodynamic diameters, thereby impeding their self-aggregation or interaction with cells in blood. ${ }^{3-4}$ In addition, the protective outerwear is able to prevent drugs from antibodies that will result in unsuccessful therapy to the most extent. ${ }^{4}$

Poly(ethylene glycol)s (PEG) are artificial and non-ionic hydrophilic polymers, which are widely used in biomedicine by covalent or non-covalent conjugation to stabilize drugs during transport. ${ }^{5-11}$ The first two complexes of proteins with PEG were PEGylated albumin and liver catalase which exhibited non-immunogenicity and extension of circulation time in blood while maintaining bioactivity of the proteins. ${ }^{12-}$ ${ }^{13}$ Later, microspheres such as poly(lactide acid-r-glycolic acid) and liposomes were modified with PEG to prolong their circulating life in vivo. ${ }^{14-17}$ PEG served as a shield to keep ionic substances such as DNA and poly(L-lysine) away from blood or organs to minimize toxicity. ${ }^{18-19}$ While PEGs with high molecular weight (MW) up to 50 $\mathrm{kg} / \mathrm{mol}$ are favored for loading small molecules to improve enhanced permeability and retention effect as well as stealth effect, the excretion of high MW PEG should be taken into account. ${ }^{11}$ Non-biodegradability is another characteristic of high MW PEG since PEG can do harm to body due to accumulation. ${ }^{7,11,20}$ Besides, PEGylated drugs have been revealed to induce immunogenicity in recent years, which will have serious impact on patients. ${ }^{21-23}$ It calls for a substitution that works as well as PEG but also covers the shortages of PEG. However, not all the non-ionic hydrophilic polymers are qualified to replace PEG.

Polysarcosine (PSar), i.e. poly( $N$-methyl glycine), is an excellent candidate. ${ }^{11,24-26}$ PSar is made of sarcosine, the endogenous amino acid in muscle tissues, and is mimetic to polyalanine but is highly water soluble. ${ }^{27-28}$ The methyl substituted amide group becomes the key factor that PSar displays limited affinity to protein, therefore prohibiting thrombus. ${ }^{29-31}$ The absence of H-bond donor also endows PSar with nonimmunogenicity because H-bond donor seems to be essential for reacting with 
antibody. ${ }^{32-34}$ Many researches have been reported in recent years that the biocompatible, non-cytotoxic and stealth-like PSar does well in biomedicine. ${ }^{25-26,35-40}$ With the same problem as PEG has, PSar is non-biodegradable and there has been no successful enzymolysis of PSar so far, indicating the excretion of PSar is nonnegligible. ${ }^{41}$ Another methylated glycine, L-alanine (Ala), is one of the native amino acids as an isomer of sarcosine. Polyalanine (PAla) is digestible by enzyme. ${ }^{42-43}$ However, PAla is not soluble in water and most organic solvents because of its secondary structures of $\alpha$-helix and $\beta$-sheet folding, which limits its biomedical application. In contrast, PSar is soluble in water, alcohol, $N, N$-dimethylformamide, chloroform, acetonitrile, etc. We propose that PSar containing randomly distributed Ala residues inside the backbone, i.e. random copolymer of poly(Ala-r-Sar) will evolve biodegradability to serve as a perfect drug coat. On the other hand, with the incorporation of sarcosine residue in the PAla backbone, i.e. poly(Ala-r-Sar) with high fraction of Ala residues, the solubility of PAla will be certainly improved. The only report of copolymer of sarcosine and alanine is back to 1978 when Kricheldorf investigated the copolypeptide by the polymerization of Ala- and Sar- $N$ carboxyanhydrides without the information of copolymerization behavior and properties of the copolymers. ${ }^{44}$

Nowadays, ring-opening polymerization (ROP) of $\alpha$-amino acid $N$ thiocarboxyanhydrides (NTA) becomes a fashionable way to synthesize tailored polypeptides or polypeptoids with high MW. Although Kricheldolf et al. found NTA and $N$-substituted NTA (NNTA) were not promising to synthesize high MW polypeptides and polypeptoids because of physical death and stabilization of thiocarbonate group by solvation, respectively, ${ }^{45}$ there has been many efforts paving the way for well-controlled ROP of NTA monomers. ${ }^{37,46-58}$ Acetic acid (HAc) catalyzes polymerizations of $\mathrm{NTA}^{54}$ and $\mathrm{NNTA}^{55}$ to overturn common sense to the most extent because researchers used to think that HAc would inactivate the amino groups at the polymer chain end and impede propagation. Nevertheless, to the best of our knowledge, the copolymerization of NTAs and NNTAs has not been reported yet. The random copolymerization of Ala-NTA and Sar-NTA is well worth investigating not only to 
understand the copolymerization behaviors but also to fabricate biodegradable PSar.

To investigate the syntheses of random copolymers of poly(Ala- $r$-Sar), abbreviated as PAS, we start with the homo-polymerization of Ala-NTA. The polymerization of Ala-NTA initiated by benzylamine (BA) in MeCN solution (Sample 1 in Table 1) encounters physical death of active chain end ${ }^{45}$ and yields white precipitation within half an hour. The white solid with high dispersity $(Ð)$ above 2 is characterized by ${ }^{1} \mathrm{H}$ NMR (Figure S2A). The copolymerization of Ala-NTA and SarNTA still yields precipitation but becomes more controllable than homo-polymerization of Ala-NTA. Both the MeCN-insoluble and MeCN-soluble parts (Sample 2A and 2B in Table 1) contain both Ala and Sar residues according to ${ }^{1} \mathrm{H}$ NMR analyses (Figure S2). These phenomena evidence that Ala-NTA is able to copolymerize with Sar-NTA in a more controllable way than homo-polymerization of Ala-NTA. The following content improves the controllability of copolymerization.

Table 1. Polymerization of Ala-NTA and Sar-NTA ${ }^{a}$

\begin{tabular}{|c|c|c|c|c|c|c|c|c|c|c|}
\hline \multirow{2}{*}{ Sample } & \multirow{2}{*}{ Ala:Sar:BA:HAc ${ }^{b}$} & \multirow{2}{*}{ Solvent } & \multirow{2}{*}{$\begin{array}{l}\text { Temp. } \\
\left({ }^{\circ} \mathrm{C}\right)\end{array}$} & \multirow{2}{*}{$\begin{array}{l}\text { Time } \\
\text { (h) }\end{array}$} & \multirow{2}{*}{$\begin{array}{l}\text { Yield } \\
(\%)\end{array}$} & \multicolumn{2}{|c|}{ Number $^{c}$} & \multirow{2}{*}{$\begin{array}{l}\text { Ala } \\
(\%)^{d}\end{array}$} & \multirow{2}{*}{$\begin{array}{c}M_{\mathrm{n}}{ }^{e} \\
(\mathrm{~kg} / \mathrm{mol})\end{array}$} & \multirow{2}{*}{$D^{e}$} \\
\hline & & & & & & Ala & Sar & & & \\
\hline 1 & 15:0:1:0 & $\mathrm{MeCN}$ & 25 & 42 & $>99$ & 10 & 0 & - & 1.4 & 2.05 \\
\hline $2 \mathrm{~A}^{f}$ & $15: 17: 1: 0$ & $\mathrm{MeCN}$ & 25 & 42 & $>99$ & 15 & 13 & 54 & 3.2 & 1.26 \\
\hline $2 \mathrm{~B}^{f}$ & $15: 17: 1: 0$ & $\mathrm{MeCN}$ & 25 & 42 & $>99$ & 9 & 11 & 45 & 2.7 & 1.36 \\
\hline 3 & $13: 32: 1: 90$ & $\mathrm{MeCN}$ & 25 & 43 & 87.6 & 12 & 27 & 31 & 5.3 & 1.13 \\
\hline 4 & 50:48:1:200 & $\mathrm{MeCN}$ & 25 & 137 & 97.6 & 48 & 49 & 49 & 11.8 & 1.09 \\
\hline 5 & 10:90:1:200 & $\mathrm{MeCN}$ & 35 & 42 & 85.7 & 8 & 70 & 10 & 11.9 & 1.10 \\
\hline 6 & 100:100:1:400 & DMAc & 60 & 66 & 87.2 & 71 & 94 & 43 & 22.0 & 1.08 \\
\hline 7 & $53: 447: 1: 1000$ & DMAc & 60 & 48 & 82.1 & 26 & 391 & 6 & 43.6 & 1.25 \\
\hline 8 & 0:500:1:1000 & DMAc & 60 & 48 & 84.8 & 0 & 460 & - & 50.9 & 1.19 \\
\hline
\end{tabular}

${ }^{a}$ Homo- or copolymerization of Ala-NTA and Sar-NTA. The initial total NTA concentration is $0.6 \mathrm{~mol} / \mathrm{L} .{ }^{b}$ The molar ratios of initial feeds. ${ }^{c}$ The number of amino acid residues in polymers, calculated by ${ }^{1} \mathrm{H}$ NMR. ${ }^{d}$ Molar fraction of Ala residues in copolymers. ${ }^{e}$ Determined by SEC. ${ }^{f}$ Products in precipitation (2A) and solution (2B) are characterized separately. 
The copolymerizations of Ala-NTA with Sar-NTA are living and controlled promoted by HAc. No precipitation is observed during the polymerization in the presence of HAc (Figure 1A and Sample 3 in Table 1). Sample 3 contains both Ala and Sar residues (Figure 1B) whose proton signals locate at 1.02 1.39 ppm (methyl groups of Ala residues), 2.64 3.12 ppm (methyl groups Sar residues) and 3.63 4.90 ppm ( $\alpha$ H). The number of Ala and Sar residues in copolymer is close to the initial ratio of [NTA]:[BA], and the SEC curve (Figure 1D) exhibits a symmetrically unimodal peak and narrow dispersity $(\nexists=1.13)$. The identical diffusion coefficient $\left(-10.6 \mathrm{~m}^{2} / \mathrm{s}\right)$ of the protons in both Sar and Ala residues is detected in DOSY NMR spectrum (Figure 1C), further confirming the involvement of two residues in the same backbone. The MALDIToF MS of Sample 3 shows a monomodal distribution, and every population is attributed to poly(methyl glycine) carrying BA chain-end and a cation (Figure 1E and 1F). With the initial [NTA]:[BA] ratio of 100 (Sample 4 and 5 in Table 1), excellent controllability of polymerization, quantitative yield and no precipitation are observed, producing PAS copolymer with high fraction of Ala residues (49\%) and low $\oslash$ of 1.09 (Sample 4 in Table 1).

${ }^{13} \mathrm{C}$ NMR, HSQC and HMBC are employed to examine the random architecture of Sample 4. Firstly, ${ }^{13} \mathrm{C}$ NMR and HSQC help to determine alkyl carbons of polymer chain (Figure $1 \mathrm{G}$ and S3). The carbon signals of methyl groups of Ala $\left(\mathrm{C}_{\mathrm{a}}\right)$ and $\operatorname{Sar}\left(\mathrm{C}_{d}\right)$ residues are located in $18.0 \mathrm{ppm}$ and $35.2 \mathrm{ppm}$, respectively, while the signals in 44.6 ppm $\left(\mathrm{C}_{\mathrm{b}}\right)$ and between 47.3 51.9 ppm $\left(\mathrm{C}_{\mathrm{c}}\right)$ are attributed to $\alpha$-carbons. Secondly, the correlation signals of $\mathrm{H}_{\mathrm{e}}-\mathrm{C}_{1}, \mathrm{H}_{\mathrm{d}}-\mathrm{C}_{4}, \mathrm{H}_{\mathrm{d}}-\mathrm{C}_{3}$ and $\mathrm{He}_{\mathrm{e}}-\mathrm{C}_{2}$ in $\mathrm{HMBC}$ spectrum demonstrate the existence of Ala-Ala, Sar-Ala, Sar-Sar and Ala-Sar diads (Figure S4A, B, C and D, respectively). These carbonyl groups of four diads in ${ }^{13} \mathrm{C}$ NMR spectrum (Figure 1G) are distinguished according to the carbonyl signals of four model molecules of $N$-ethyl acetamide, $N, N$-dimethyl acetamide, $N, N$-dimethyl propionamide and $N$-ethyl propionamide which locate at 168.8, 169.6, 172.6 and $172.5 \mathrm{ppm}$, respectively (Figure S5). 

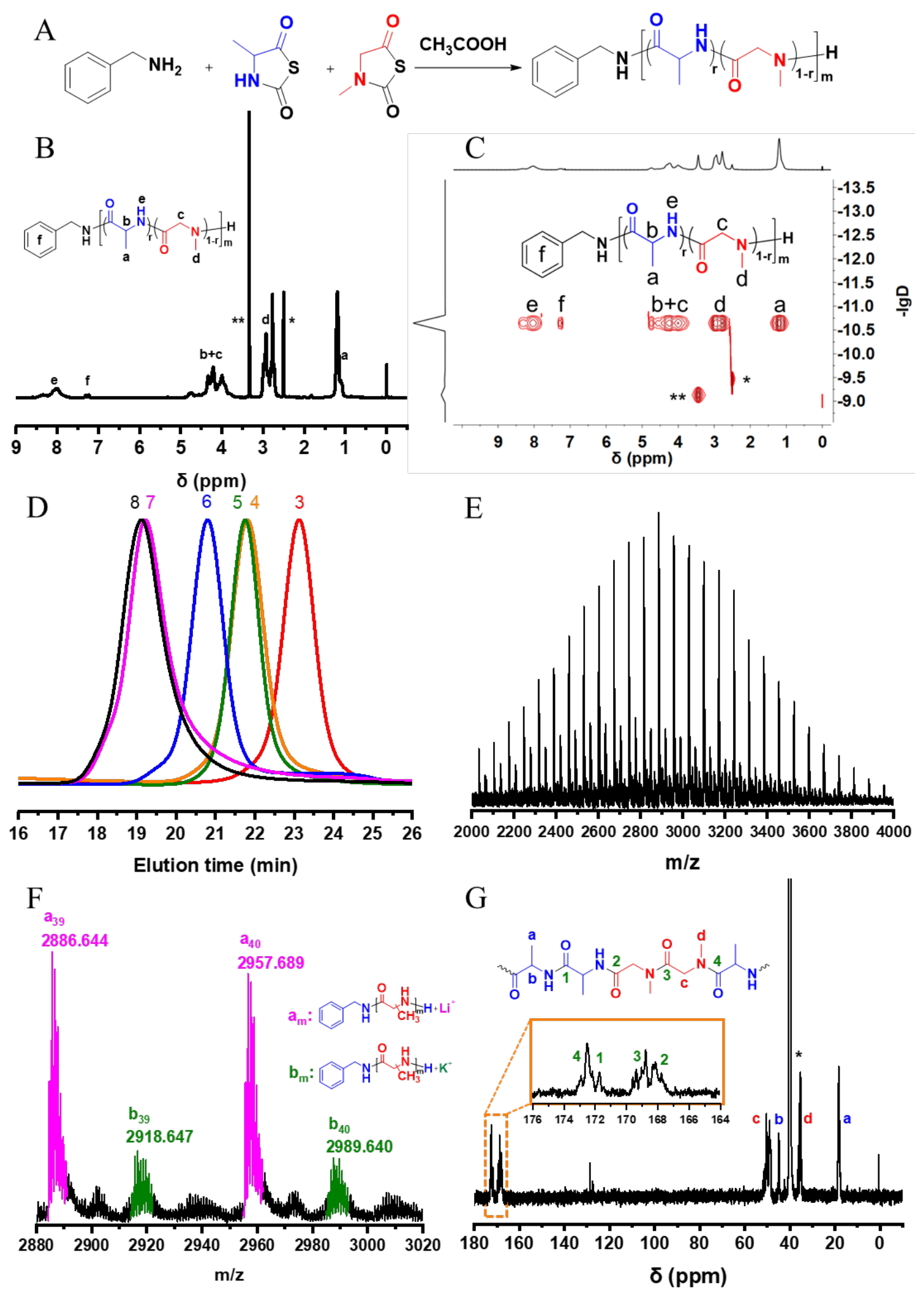

Figure 1. (A) Synthesis of PAS by the random copolymerization of Ala-NTA with SarNTA. (B) ${ }^{1} \mathrm{H}$ NMR and (C) DOSY spectra of PAS where * and ** represent DMSO and water, respectively. (D) SEC traces of copolymers and homo-PSar with the same serial numbers in Table 1. (E) MALDI-ToF MS of Sample 4 in Table 1 with (F) a zoom-in 
view and corresponding structures. (G) ${ }^{13} \mathrm{C}$ NMR spectrum with a zoom-in view of PAS, *: DMSO.

The copolymerization kinetics are investigated and the time-dependent ${ }^{1} \mathrm{H}$ NMR spectra are shown in Figure S6. Both Ala-NTA and Sar-NTA exhibit pseudo-first-order kinetics (Figure S7). The linear $\ln \left([\mathrm{M}]_{0} /[\mathrm{M}]_{\mathrm{t}}\right)$ versus time plots reveal the livingness of polymerization and determine the comparable apparent polymerization rate constants $(k)$ of Sar-NTA $\left(3.66 \times 10^{-3} \mathrm{~min}^{-1}\right)$ and Ala-NTA $\left(2.02 \times 10^{-3} \mathrm{~min}^{-1}\right)$. The molar fractions of the two amino acid residues in PAS keep close to 50\% during copolymerization (Figure S8), indicating a random distribution of Ala and Sar residues along the backbone.

We synthesize PAS with high MW (22.0 50.9 kg/mol) and narrow $Ð$ (within 1.25) containing Ala residues of $0 \%, 6 \%$ and 43\% (Sample 8, 7 and 6 in Table 1 and Figure $1 \mathrm{D}$, respectively) and explore their degradation behaviors in the presence of enzyme. The mixtures of $7 \mathrm{mg}$ PAS with $70 \mathrm{mg}$ porcine pancreatic elastase (PPE) in $2 \mathrm{~mL}$ phosphate buffered saline are kept under $37^{\circ} \mathrm{C}$ for 0,25 and 50 days. Not surprisingly, PSar homopolymer (Sample 8 in Table 1) cannot be digested by PPE after 50 days (Figure 2A). On the contrary, the SEC peak of the PAS containing 6\% Ala (Sample 7 in Table 1) shifts to lower MW side, and the molecular weight at peak $\left(M_{\mathrm{p}}\right)$ decreases by $8 \%$ after enzymolysis over 50 days (Figure $2 \mathrm{~B}$ ). It is more obvious that the PAS with $43 \%$ Ala (Sample 6 in Table 1) is completely digested within 50 days since there is no detectable PAS in SEC (Figure 2C). The introduction of Ala residues in PAS backbone enables its biodegradability by PPE in mild condition, and the degradation rate increases with the content of Ala residues. 
A

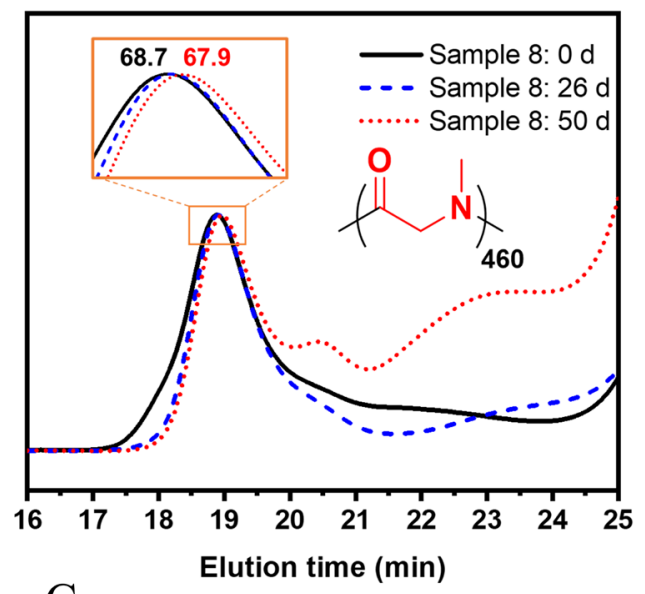

$\mathrm{C}$

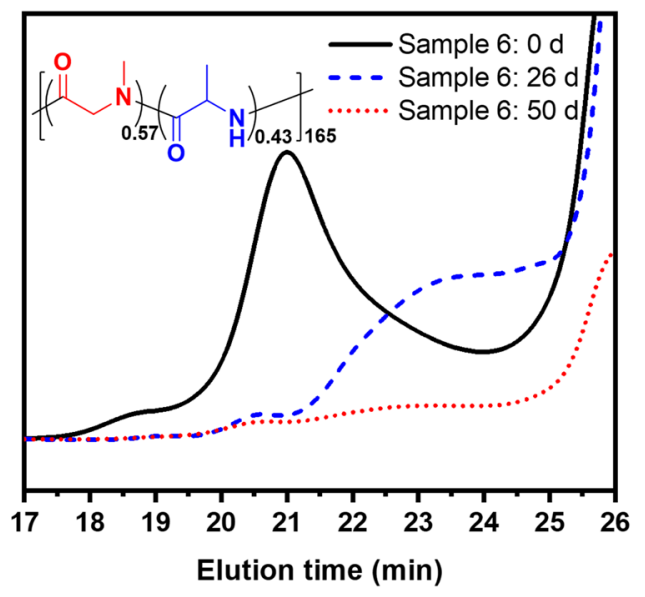

$\mathrm{B}$

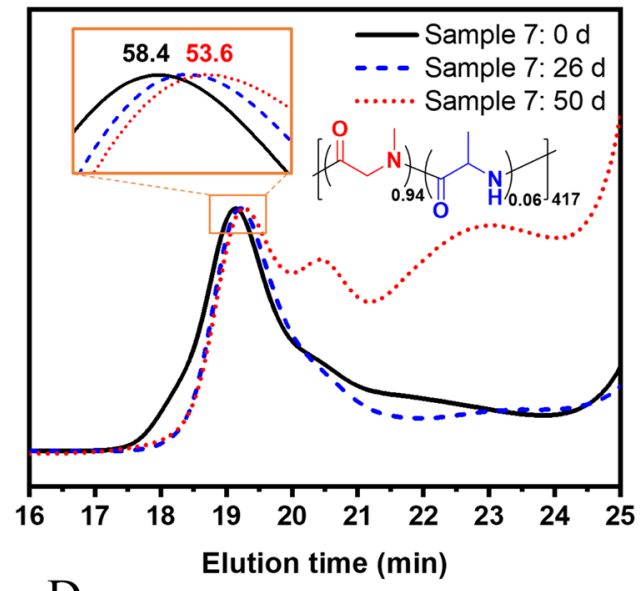

$\mathrm{D}$

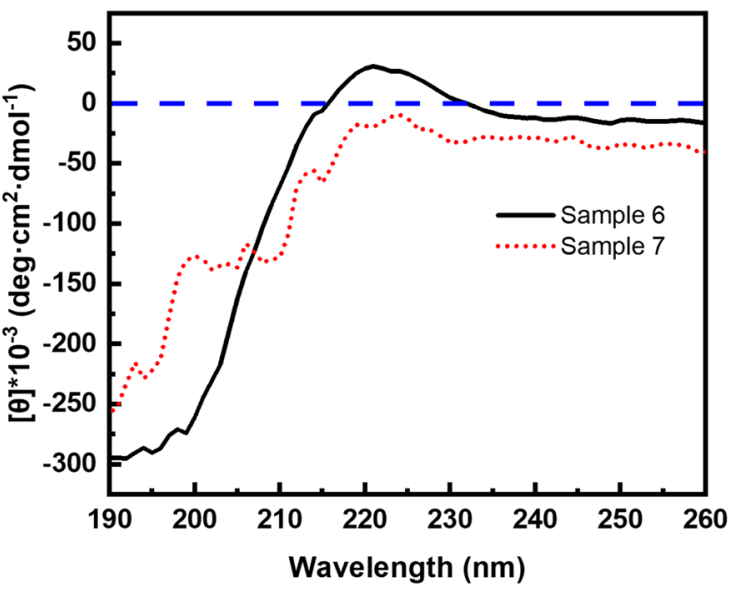

Figure 2. (A, B and C) SEC traces of PAS that hydrolyzed by PPE for 0 day (black solid line), 26 days (blue dash line) and 50 days (red dot line). The zoom-in views show $M_{\mathrm{p}}$ of PAS before and after enzymolysis for 50 days. The elution time of PPE is between 20 24 min, which overlaps that of degraded PAS. (D) CD spectra of PAS.

As PAla is easy to form $\beta$-sheet conformation, it is appealing to characterize the secondary structure in PAS. Circular dichroism (CD) spectra (Figure 2D) illustrate a random coil for PAS with 6\% Ala (Sample 7) and an extended 31-helical structure for PAS with 43\% Ala (Sample 6). ${ }^{59}$ The random architecture of PAS is responsible for the fact that neither $\alpha$-helix nor $\beta$-sheet folding is formed. The hydrophobicity and secondary structure of Sample 6 are driving forces for PAS to self-assemble into nanoparticles in water, and the average hydrodynamic diameter is c.a. $230 \mathrm{~nm}$ by dynamic lighting scattering (DLS) (Figure 3A). Besides cooperating with other hydrophobes, PAS itself is qualified as a drug-carrier. 
For further application of PAS in living bodies, the biocompatibility of PAS is assessed using cell viability test with CCK-8 as indicator. Two copolymers (Sample 6 and 7 in Table 1) at various concentrations are incubated with NIH $3 \mathrm{~T} 3$ cells at $37{ }^{\circ} \mathrm{C}$. As presented in Figure 3B, the tested cells remain relative cell viability over $100 \%$ after incubating for $24 \mathrm{~h}$ with concentration of PAS as high as $5 \mathrm{mg} / \mathrm{mL}$. Thus, the in vitro cell viability elucidates PAS to be non-cytotoxic.
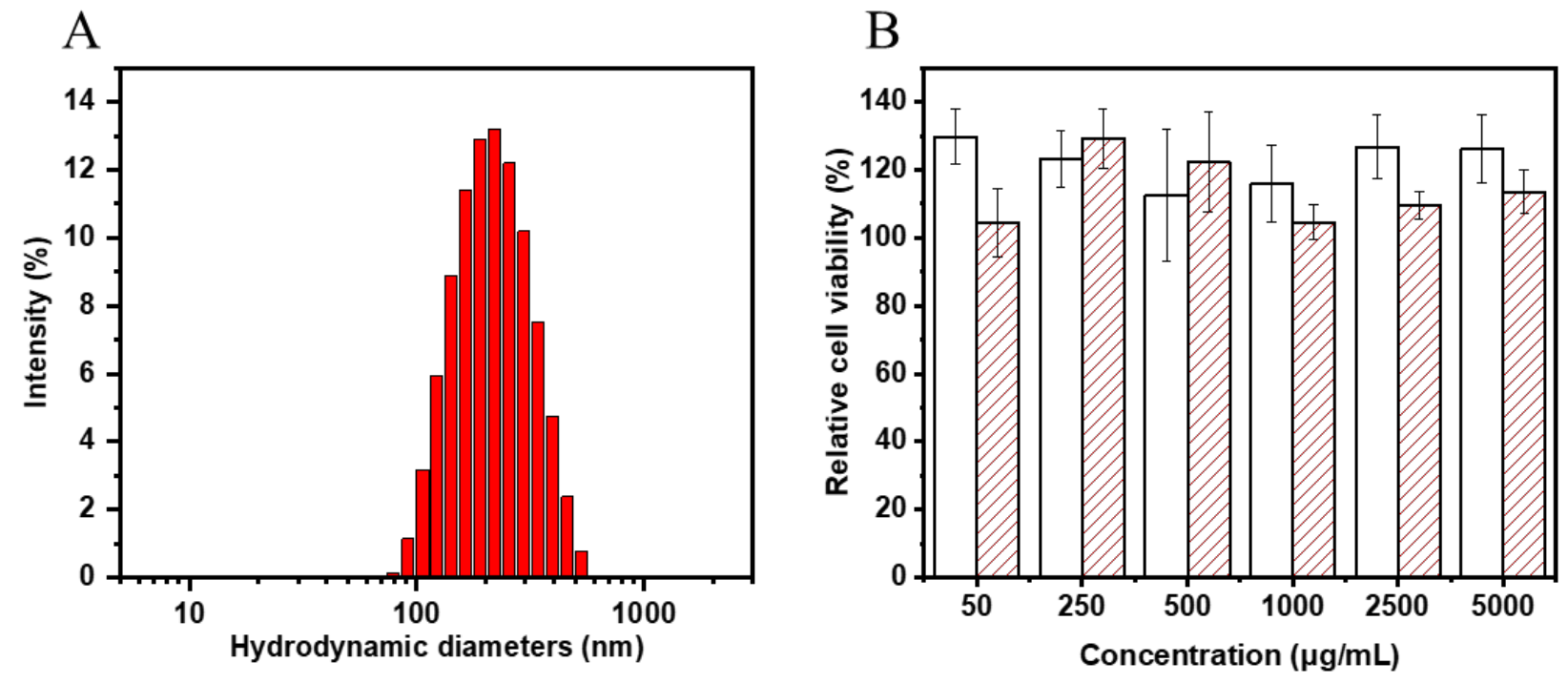

Figure 3. (A) DLS result of PAS nanoparticles from Sample 6 in Table 1. (B) Relative cell viability of PAS (Sample 6 (blank) and 7 (slash) in Table 1) for NIH 3 T3 cells after incubation at $37{ }^{\circ} \mathrm{C}$ for $24 \mathrm{~h}$ with concentration of PAS between 50 and $5000 \mu \mathrm{g} / \mathrm{mL}$.

In conclusion, we present a synthetic approach of PAS as a biodegradable PSar with randomly inserted Ala residues via ring-opening copolymerization of Ala-NTA with Sar-NTA in the presence of HAc. The well-controlled copolymerization produces random copolymers with designable DPs and narrow dispersity $(\fallingdotseq<1.25)$. Both AlaNTA and Sar-NTA show pseudo-first-order characteristics according to kinetics study, and the consumption of the former is slightly slower. PAS with high MW (22.0 43.6 $\mathrm{kg} / \mathrm{mol}$ ) and tunable contents of Ala residues varying from $6 \%$ to $43 \%$ can be digested by PPE at different rates of enzymolysis. The biodegradability and non-toxicity make PAS a promising biomaterial as an alternative of PEG in drug-delivery applications. 


\section{Supporting Information}

Experimental section, characterization of NTA monomers and polymers, kinetics and enzymolysis studies.

\section{Conflicts of interest}

The authors declare no financial conflicts.

\section{Acknowledgement}

Financial support by the National Natural Science Foundation of China (21871232) and the Key Research and Development Program of Zhejiang Province (2019C03014).

\section{References}

1. Tibbitt, M. W.; Dahlman, J. E.; Langer, R., Emerging Frontiers in Drug Delivery. J. Am. Chem. Soc. 2016, 138 (3), 704-717.

2. Li, J.; Mooney, D. J., Designing hydrogels for controlled drug delivery. Nat. Rev. Mater. 2016, 1 (12), 1-17.

3. Pasut, G.; Veronese, F. M., State of the art in PEGylation: the great versatility achieved after forty years of research. J. Control. Release 2012, 161 (2), 461-472.

4. Hu, J.; Wang, G.; Zhao, W.; Gao, W., In situ growth of a $C$-terminal interferon-alpha conjugate of a phospholipid polymer that outperforms PEGASYS in cancer therapy. J. Control. Release 2016, 237, 71-77.

5. Choe, Y. H.; Conover, C. D.; Wu, D.; Royzen, M.; Gervacio, Y.; Borowski, V.; Mehlig, M.; Greenwald, R. B., Anticancer drug delivery systems: multi-loaded $N^{4}$-acyl poly(ethylene glycol) prodrugs of ara-C. II. Efficacy in ascites and solid tumors. J. Control. Release 2002, 79, 55-70.

6. Schiavon, O.; Pasut, G.; Moro, S.; Orsolini, P.; Guiotto, A.; Veronese, F. M., PEG-Ara-C conjugates for controlled release. Eur. J. Med. Chem. 2004, 39 (2), 123-133.

7. Pasut, G.; Veronese, F. M., Polymer-drug conjugation, recent achievements and general strategies. Prog. Polym. Sci. 2007, 32 (8-9), 933-961.

8. Berna, M.; Dalzoppo, D.; Pasut, G.; Manunta, M.; Izzo, L.; Jones, A. T.; Duncan, R.; Veronese, F. M., Novel Monodisperse PEG-Dendrons as New Tools for Targeted Drug Delivery: Synthesis, Characterization and Cellular Uptake. Biomacromolecules 2006, 7, 146-153.

9. Yang, K.; Basu, A.; Wang, M.; Chintala, R.; Hsieh, M. C.; Liu, S.; Hua, J.; Zhang, Z.; Zhou, J.; Li, M.; Phyu, H.; Petti, G.; Mendez, M.; Janjua, H.; Peng, P.; Longley, C.; Borowski, V.; Mehlig, M.; Filpula, D., Tailoring structure-function and pharmacokinetic properties of single-chain Fv proteins by site-specific PEGylation. Protein Eng. 2003, 16 (10), 761-770.

10. Allen, T. M.; Cullis, P. R., Drug Delivery Systems: Entering the Mainstream. Science 2004, 
$303,1818-1822$.

11. Knop, K.; Hoogenboom, R.; Fischer, D.; Schubert, U. S., Poly(ethylene glycol) in drug delivery: pros and cons as well as potential alternatives. Angew. Chem.-Int. Ed. 2010, 49 (36), 6288-6308.

12. Abuchowski, A.; Mccoy, J. R.; Palczuk, N. C.; Van Es, T.; Davis, F. F., Effect of covalent attachment of polyethylene glycol on immunogenicity and circulating life of bovine liver catalase. J. Biol. Chem. 1977, 252 (11), 3582-3586.

13. Abuchowski, A.; Van Es, T.; Palczuk, N. C.; Davis, F. F., Alteration of immunological properties of bovine serum albumin by covalent attachment of polyethylene glycol. J. Biol. Chem. 1977, 252 (11), 3578-3581.

14. Gref, R.; Minamitake, Y.; Peracchia, M. T.; Trubetskoy, V.; Torchilin, V.; Langer, R., Biodegradable Long-Circulating Polymeric Nanospheres. Science 1994, 263, 1600-1603.

15. Kreuter, J., Nanoparticles-a historical perspective. Int. J. Pharm. 2007, 331 (1), 1-10.

16. Torchilin, V. P., Recent advances with liposomes as pharmaceutical carriers. Nat. Rev. Drug Discov. 2005, 4 (2), 145-160.

17. Lasic, D. D.; Needham, D., The "Stealth" Liposome: A Prototypical Biomaterial. Chem. Rev. 1995, 95 (8), 2601-2628.

18. Nguyen, H.-K.; Lemieux, P.; Vinogradov, S.; Gebhart, C.; Guerin, N.; Paradis, G.; Bronich, T.; Alakhov, V.; Kabanov, A., Evaluation of polyether-polyethyleneimine graft copolymers as gene transfer agents. Gene Ther. 2000, 7, 126-138.

19. Oupicky, D.; Ogris, M.; Howard, K. A.; Dash, P. R.; Ulbrich, K.; Seymour, L. W., Importance of lateral and steric stabilization of polyelectrolyte gene delivery vectors for extended systemic circulation. Mol. Ther. 2002, 5 (4), 463-472.

20. Veronese, F. M.; Pasut, G., PEGylation, successful approach to drug delivery. Drug Discov. Today 2005, 10 (21), 1451-1458.

21. Shiraishi, K.; Hamano, M.; Ma, H.; Kawano, K.; Maitani, Y.; Aoshi, T.; Ishii, K. J.; Yokoyama, M., Hydrophobic blocks of PEG-conjugates play a significant role in the accelerated blood clearance (ABC) phenomenon. J. Control. Release 2013, 165 (3), 183-190.

22. Mima, Y.; Hashimoto, Y.; Shimizu, T.; Kiwada, H.; Ishida, T., Anti-PEG IgM Is a Major Contributor to the Accelerated Blood Clearance of Polyethylene Glycol-Conjugated Protein. Mol. Pharm. 2015, 12 (7), 2429-2435.

23. Calabrese, L. H.; Kavanaugh, A.; Yeo, A. E.; Lipsky, P. E., Frequency, distribution and immunologic nature of infusion reactions in subjects receiving pegloticase for chronic refractory gout. Arthritis Res. Ther. 2017, 19 (1), 191.

24. Pelegri-O'day, E. M.; Lin, E.-W.; Maynard, H. D., Therapeutic Protein-Polymer Conjugates: Advancing Beyond PEGylation. J. Am. Chem. Soc. 2014, 136 (41), 14323-14332.

25. Hu, Y.; Hou, Y.; Wang, H.; Lu, H., Polysarcosine as an Alternative to PEG for Therapeutic Protein Conjugation. Bioconjugate Chem. 2018, 29 (7), 2232-2238.

26. Varlas, S.; Georgiou, P. G.; Bilalis, P.; Jones, J. R.; Hadjichristidis, N.; O'reilly, R. K., Poly(sarcosine)-Based Nano-Objects with Multi-Protease Resistance by Aqueous Photoinitiated Polymerization-Induced Self-Assembly (Photo-PISA). Biomacromolecules 2018, 19 (11), 4453-4462.

27. Mudd, S. H.; Ebert, M. H.; Scriver, C. R., Labile Methyl Group Balances in the Human: The Role of Sarcosine. Metab.-Clin. Exp. 1980, 29 (8), 707-720. 
28. Birke, A.; Ling, J.; Barz, M., Polysarcosine-containing copolymers: Synthesis, characterization,self-assembly, and applications. Prog. Polym. Sci. 2018, 81, 163-208.

29. Lau, K. H. A.; Ren, C.; Sileika, T. S.; Park, S. H.; Szleifer, I.; Messersmith, P. B., SurfaceGrafted Polysarcosine as a Peptoid Antifouling Polymer Brush. Langmuir 2012, 28 (46), 16099-16107.

30. Ostuni, E.; Chapman, R. G.; Holmlin, R. E.; Takayama, S.; Whitesides, G. M., A Survey of Structure-Property Relationships of Surfaces that Resist the Adsorption of Protein. Langmuir 2001, 17, 5605-5620.

31. Chapman, R. G.; Ostuni, E.; Takayama, S.; Holmlin, R. E.; Yan, L.; Whitesides, G. M., Surveying for Surfaces that Resist the Adsorption of Proteins. J. Am. Chem. Soc. 2000, 122, 8303-8304.

32. Sela, M., Immunological Studies with Synthetic Polypeptides. Adv.Immunol. 1966, 5, 29-129.

33. Maurer, P. H.; Subrahmanyam, D.; Katchalski, E.; Blout, E. R., Antigenicity of Polypeptides (Poly Alpha Amino Acids). J. Immunol. 1959, 83, 193-197.

34. Kricheldorf, H. R., Polypeptides and 100 Years of Chemistry of alpha-Amino Acid $N$ carboxyanhydrides. Angew. Chem.-Int. Ed. 2006, 45 (35), 5752-5784.

35. Nogueira, S. S.; Schlegel, A.; Maxeiner, K.; Weber, B.; Barz, M.; Schroer, M. A.; Blanchet, C. E.; Svergun, D. I.; Ramishetti, S.; Peer, D.; Langguth, P.; Sahin, U.; Haas, H., PolysarcosineFunctionalized Lipid Nanoparticles for Therapeutic mRNA Delivery. ACS Appl. Nano Mater. 2020, 3 (11), 10634-10645.

36. Huesmann, D.; Sevenich, A.; Weber, B.; Barz, M., A Head-to-Head Comparison of Poly(Sarcosine) and Poly(Ethylene Glycol) in Peptidic, Amphiphilic Block Copolymers. Polymer 2015, 67, 240-248.

37. Tao, X.; Deng, C.; Ling, J., PEG-Amine-Initiated Polymerization of Sarcosine $N$ thiocarboxyanhydrides toward Novel Double-Hydrophilic PEG- $b$-Polysarcosine Diblock Copolymers. Macromol. Rapid Commun. 2014, 35 (9), 875-881.

38. Deng, Y.; Zou, T.; Tao, X.; Semetey, V.; Trepout, S.; Marco, S.; Ling, J.; Li, M.-H., Poly(epsilon-caprolactone)-block-polysarcosine by Ring-Opening Polymerization of Sarcosine $N$-Thiocarboxyanhydride: Synthesis and Thermoresponsive Self-Assembly. Biomacromolecules 2015, 16 (10), 3265-3274.

39. Yan, Q.; Dong, X.; Xie, R.; Xu, X.; Wang, X.; Zhang, K.; Xia, J.; Ling, J.; Zhou, F.; Sun, J., Preparation of $\mathrm{Mn}^{2+} @$ PolyDOPA- $b$-Polysarcosine Micelle as MRI Contrast Agent with High Longitudinal Relaxivity. J. Macromol. Sci. Part A-Pure Appl. Chem. 2020, 58 (3), 175-181.

40. Birke, A.; Huesmann, D.; Kelsch, A.; Weilbacher, M.; Xie, J.; Bros, M.; Bopp, T.; Becker, C.; Landfester, K.; Barz, M., Polypeptoid-block-Polypeptide Copolymers: Synthesis, Characterization, and Application of Amphiphilic Block Copolypept(o)ides in Drug Formulations and Miniemulsion Techniques. Biomacromolecules 2014, 15 (2), 548-557.

41. Barz, M.; Luxenhofer, R.; Zentel, R.; Vicent, M. J., Overcoming the PEG-addiction: welldefined alternatives to PEG, from structure-property relationships to better defined therapeutics. Polym. Chem. 2011, 2 (9), 1900-1918.

42. Jeong, Y.; Joo, M. K.; Bahk, K. H.; Choi, Y. Y.; Kim, H. T.; Kim, W. K.; Lee, H. J.; Sohn, Y. S.; Jeong, B., Enzymatically degradable temperature-sensitive polypeptide as a new in-situ gelling biomaterial. J. Control. Release 2009, 137 (1), 25-30.

43. Moon, H. J.; Choi, B. G.; Park, M. H.; Joo, M. K.; Jeong, B., Enzymatically degradable 
thermogelling poly(alanine-co-leucine)-poloxamer-poly(alanine-co-leucine). Biomacromolecules 2011, 12 (4), 1234-1242.

44. Kricheldorf, H. R.; Schilling, G., ${ }^{13} \mathrm{C}$ NMR sequence analysis, 15. Copolymerization of alanine-NCA with other $\alpha$-amino acid NCAs. Makromol. Chem. 1978, 179, 1175-1191.

45. Kricheldorf, H. R.; Sell, M.; Schwarz, G., Primary Amine-Initiated Polymerizations of $\alpha-$ Amino Acid N-Thiocarbonic Acid Anhydrosulfide. J. Macromol. Sci. Part A-Pure Appl. Chem. 2011, 45 (6), 425-430.

46. Tao, X.; Deng, Y.; Shen, Z.; Ling, J., Controlled Polymerization of $N$-Substituted Glycine $N$ Thiocarboxyanhydrides Initiated by Rare Earth Borohydrides toward Hydrophilic and Hydrophobic Polypeptoids. Macromolecules 2014, 47 (18), 6173-6180.

47. Tao, X.; Zheng, B.; Bai, T.; Zhu, B.; Ling, J., Hydroxyl Group Tolerated Polymerization of $N$ Substituted Glycine $N$-Thiocarboxyanhydride Mediated by Aminoalcohols: A Simple Way to $\alpha$-Hydroxyl- $\omega$-aminotelechelic Polypeptoids. Macromolecules 2017, 50 (8), 3066-3077.

48. Tao, X.; Zheng, B.; Kricheldorf, H. R.; Ling, J., Are $N$-Substituted Glycine $N$ Thiocarboxyanhydride Monomers Really Hard to Polymerize? J. Polym. Sci. Pol. Chem. 2017, 55 (3), 404-410.

49. Tao, X.; Zheng, B.; Bai, T.; Li, M.-H.; Ling, J., Polymerization of $N$-Substituted Glycine $N$ Thiocarboxyanhydride through Regioselective Initiation of Cysteamine: A Direct Way toward Thiol-Capped Polypeptoids. Macromolecules 2018, 51 (12), 4494-4501.

50. Zheng, B.; Bai, T.; Ling, J.; Sun, J., Direct $N$-Substituted $N$-Thiocarboxyanhydride Polymerization towards Polypeptoids Bearing Unprotected Carboxyl Groups. Comm. Chem. 2020, 3 (144).

51. Cao, J.; Siefker, D.; Chan, B. A.; Yu, T.; Lu, L.; Saputra, M. A.; Fronczek, F. R.; Xie, W.; Zhang, D., Interfacial Ring-Opening Polymerization of Amino-Acid-Derived NThiocarboxyanhydrides Toward Well-Defined Polypeptides. ACS Macro Lett. 2017, 6 (8), 836840.

52. Bai, T.; Zhou, P.; Li, Z.; Zheng, B.; Ling, J., Seeding Crystals, Harvesting Polypeptides: Preparing Long Chiral-Sequence Controlled Polypeptides by Interlocked Polymerization in Cocrystals (iPiC) of $N$-Thiocarboxyanhydride (NTA) at Room Temperature. Macromolecules 2021, 54 (14), 6691-6697.

53. Zheng, B.; Bai, T.; Tao, X.; Schlaad, H.; Ling, J., Identifying the Hydrolysis of Carbonyl Sulfide as a Side Reaction Impeding the Polymerization of $\mathrm{N}$-Substituted Glycine $\mathrm{N}$ Thiocarboxyanhydride. Biomacromolecules 2018, 19 (11), 4263-4269.

54. Siefker, D.; Williams, A. Z.; Stanley, G. G.; Zhang, D., Organic Acid Promoted Controlled Ring-Opening Polymerization of $\alpha$-Amino Acid-Derived $N$-thiocarboxyanhydrides (NTAs) toward Well-defined Polypeptides. ACS Macro Lett. 2018, 7 (10), 1272-1277.

55. Zheng, B.; Xu, S.; Ni, X.; Ling, J., Understanding Acid-Promoted Polymerization of the $\mathrm{N}$ Substituted Glycine $N$-Thiocarboxyanhydride in Polar Solvents. Biomacromolecules 2021, 22 (4), 1579-1589.

56. Zhou, P.; Shen, T.; Ling, J., Synthesis and properties of polypeptoid-containing block copolymers: A review. J. Polym. Sci. 2021, 10.1002/pol.20210507.

57. Zheng, B.; Bai, T.; Tao, X.; Ling, J., An Inspection into Multifarious Ways to Synthesize Poly(Amino Acid)s. Macromol. Rapid Commun. 2021, 10.1002/marc.202100453, e2100453.

58. Zheng, B.; Tao, X.; Ling, J., Water Tolerated Polymerization of $N$-Substituted Glycine $N$ - 
Thiocarboxyanhydride Initiated by Primary Amines. Acta Polym. Sin. 2018, 1, 72-79.

59. Kelly, S. M.; Jess, T. J.; Price, N. C., How to study proteins by circular dichroism. BBAProteins Proteomics 2005, 1751 (2), 119-139. 